\title{
Commissioning mental health services: role of the consultant psychiatrist
}

\author{
Chris Simpson
}

The current National Health Service (NHS) approach to commissioning health services is in flux. The purchasing of care from providers by general practitioner fundholders (GPFHs) and health authorities has changed with the new White Papers. GPFHs no longer exist and the commissioning role is being handed over from health authorities to primary care groups (PCGs). An understanding of the reasons for change and current arrangements will aid the consultant psychiatrist in influencing this process.

Commissioning mental health services is a poorly developed area with little expert knowledge or experience. However, it is part of the process by which tax payers' money is allocated from central government to treat our patients. It is essential that consultant psychiatrists are involved in this process so as to ensure the optimum funding to meet the needs people with mental illnesses. Owing to the poor knowledge base in health authorities and PCGs, consultant psychiatrists are in a prime position to improve the funding of our patients' services.

In this article I will look at the background to the development of commissioning and explain the commissioning process and the possible ways that consultant psychiatrists can influence it.

\section{Commissioning in the NHS}

\section{Reasons for the NHS and Community Care Act 1990}

Up until the 1980s, there was relative consensus about the funding and objectives of the NHS, a consensus that has never returned and that has resulted in bitter political arguments over rationing and priorities. The expectations of the population increased whereas the Conservative Government wanted to restrain increasing expenditure and improve efficiency. They began to look at managerial methods of controlling the money spent on what they saw as a bottomless pit. The Resource Allocation Working Party formula for re-distributing money was the first attempt to allocate NHS money on the basis of population size and need. It proved difficult as it meant the withdrawal of money from London to redistribute to other areas in the country. The Griffiths report (1983) on health service management and the introduction of resource management initiatives were developed as methods of controlling expenditure (Klein, 1995).

Public concern increased and this resulted in the Government's review of services and the resulting NHS and Community Care Act 1990. Prior to this, money was provided from the treasury to the clinical services, but this was not based upon any assessment of output. As a consequence, good services that attracted more patients often experienced financial problems, while worse services remained within budget. The Conservative Government's dislike of nationalised organisations and its embracing of free market ideals, together with its desire to control spending, steered the review and the resulting Act.

\section{Purchaser/provider split}

It was the 1990 Act that brought in the purchaser / provider split (Burns \& Bhugra, 1995). There was a clear separation between those who purchased secon-

Chris Simpson is a consultant general adult psychiatrist working in North Yorkshire (Friarage Hospital, Northallerton, North Yorkshire, DL6 1JG). He has developed a community mental health service in this largely rural area with close links with primary care. He is the Divisional Clinical Director of Mental Health Services and has a particular interest in developing mental health commissioning. 
dary care services (health authorities) and those who provided these services (NHS trusts). The NHS trusts were stand-alone bodies that could organise themselves with few constraints. Similarly, primary care services had purchasers (family practitioner committees, which later merged with health authorities) and providers (GPs). In addition, GPs could become purchasers of secondary health care services as GPFHs.

In order to determine which services would be provided and what money was to change hands between the purchasers and providers, a contract was negotiated. This was a system used in other countries (e.g. the USA) and also, of course, within industry. Indeed, in the commercial world, contracts are the legal mechanism by which parties agree to exchange something. There is a large body of case law relating to such contracts, but much of this was irrelevant within these reforms because within the NHS internal market, one part of the NHS contracted with another part (Glynn \& Murphy, 1995). However, within the contracts, specific terms had to be laid down that resulted in explicit and specified agreements between parts of the NHS. For markets to function effectively, purchasers must be sufficiently well-informed to be able to determine the value of what is offered relative to the resources available to them. General practitioners (at an individual level) and health authorities (at a population level) were believed to be sufficiently well-informed to act as agents for the public.

There is no evidence that such a purchaser/provider split can produce any benefits. The USA was the place where the Government looked for inspiration in this area, despite the American system being at breaking point. The big insurance companies are the main purchasers in the USA, but for those unable to buy health insurance owing to poverty and unemployment (i.e. the majority of people with severe mental illnesses), the government system of Medicaid is the purchaser. There are different systems of Medicaid according to the state, county or city, with different funding agencies for welfare, housing and support services. This makes comparisons difficult with mental health services in the UK. However, the better-functioning mental health services in the USA appear to be those that have close working relationships between state, county and city. Indeed, it appears to be the management, coordination and cooperation of the purchaser/provider split, with specific details in the contract, that results in better care, as opposed to leaving the free market to rule (Butler, 1993).

\section{Problems for mental health services}

As a result of this contracting process, there were a number of difficulties for mental health services (Simpson, 1998).

\section{Development of GPFHs}

This produced a split in purchasing between different elements of mental health services. Normally, it was the health authorities who purchased in-patient beds, and out-patient and community services were purchased by GPFHs. Some GPFHs began to purchase improved services for people with mild to moderate mental illnesses at the expense of those with severe mental illnesses. This created tensions between GPFHs, health authorities, who were developing strategies for mental health, and provider units.

\section{Extension of the GPFH role}

To complicate matters, the range of services bought by GPFHs changed over the years. Initially, it just included certain members of the community mental health teams and then it changed to include more members. This cut across the team approach of the community mental health teams. For instance, in one area, community psychiatric nurses could have contracts with GPFHs, whereas psychiatrists and psychologists had contracts with the health authority. Each contract specified different quality standards.

Problems with transferring general contracts to mental health

Most contracts used activity as a measurement (described, in management jargon, as activity as a 'currency'). It may be reasonable to purchase a certain amount of hip replacements or cataract operations, but using activity as a measure in mental health has major flaws:

- In mental health, the prediction of outcomes from the diagnosis is notoriously unreliable; someone with, say, schizophrenia may end up in a special hospital for the rest of their lives after first diagnosis or be treated in the community with no admission

- Mental health services provide a health promotion role including liaison with primary care through telephone contact, meetings and educational activities, none of which is measured through patient activity

- The use of contacts as a measure is misleading; the numbers of patients being seen is of little relevance, whereas smaller case-loads of patients with specific illnesses seen for longer is more in keeping with good practicemeasuring contacts just gives information on contacts, not necessarily quality or therapeutic benefit

- If a mental health service increases its income by admitting patients, then there is a perverse incentive against the principles of community care. 


\section{Psychiatrist involvement}

Within this process, GPFHs became very involved in the contracting process. Their knowledge of mental health problems was based on assumption as $90 \%$ of people with mental health problems are treated purely in primary care. Similarly, public health consultants in the health authorities were involved in the contracting process. However, over the years, there was an increase in consultant psychiatrist involvement (Simpson, 1997). The NHS Executive (1995) made strong recommendations that clinicians should be involved in the contracting process - which resulted in far more consultant psychiatrists being directly involved. This was particularly appropriate as consultant psychiatrists are in the best position to know the needs of people with mental illnesses as a result of their training. The involvement of clinicians leads to dialogue about quality, whereas managers talk about quantity.

\section{The new NHS}

The Labour Government produced three White Papers for the NHS in England, Scotland and Wales (NHS Executive, 1997a,b,c) (see Box 1). There were two essential reasons for the changes:

- the Labour Government believed that the internal market was based on competition that stifled cooperation

- there was inequality in health care provision by different purchasers.

\section{The White Paper in England}

The New NHS: Modern, Dependable (NHS Executive, 1997c) was based on four elements:

\section{Equity}

Services had been purchased from different bodies so that, for instance, access to services was determined by whether your GP was a fundholder rather than by your health needs. As a result, the White Paper recommended setting up PCGs, which have four possible options:

(a) at a minimum, supporting the health authority in commissioning care for its population, acting in an advisory capacity;

(b) taking devolved responsibility for managing the budget for health care in their area, although remaining formally part of the health authority; (c) becoming established as free-standing bodies accountable to the health authority for commissioning care; or

(d) as above, but with added responsibility for the provision of community health services for their population.

With time, these bodies can become trusts themselves.

The National Service Frameworks (NSFs) are part of this drive for equity, and the Government chose mental health as one of the first major care areas to tackle. The mental health NSF for working-age adults was published in September 1999 (NHS Executive, 1999).

\section{Quality}

As developments took place over the past 10 years, some services improved more than others. The White Paper ensures that there is a Commission for Health Improvement, and clinical governance determines quality at all levels within the system. Clinical governance is an initiative to assure and improve clinical

Box 1. The new NHS in England

Role of health authorities

Assessing health needs

Developing Health Improvement Programmes

Deciding on range and location of health care services

Determining local targets and standards

Developing PCGs

Holding PCGs to account

Role of NHS trusts

Participate in strategy and planning

Implement quality and efficiency standards

Be involved in Health Improvement Programmes

Develop clinical governance arrangements

Re-invest efficiency gains

Role of PCGs

Contribute to Health Improvement Programmes

Promote health of the population

Commission health services

Monitor performance

Develop primary care

Improve integration of primary and community services

Work closely with social services 
standards at local level throughout the NHS. This includes action to ensure that: risks are avoided; adverse events are rapidly detected, openly investigated and lessons learnt; good practices are rapidly disseminated; and that systems are in place to ensure continuous improvements in clinical care. Clinical governance will become increasingly important, with each trust and PCG having staff responsible for ensuring that quality, audit, review and risk assessment become part of normal clinical practice.

\section{Efficiency}

This includes cutting bureaucracy and new ways of looking at performance, as the market incentives have been lost. There appears to be an attempt to combine the evaluation of efficiency and quality. Each mental health service will be expected to deliver on efficiency gain by demonstrating a real cost reduction in current services. Ideal types of service (from a qualitative angle) are to be identified, and benchmarked cost targets (see Box 5) derived from them, which will then be set for all providers. The National Institute for Clinical Excellence (NICE) is being developed to promote clinical and cost-effectiveness. This is likely to indicate a development in evidencebased medicine and possibly even the removal of some treatments from the NHS.

\section{Cooperation}

The idea of cooperation is based on more modern managerial thinking about the supply chain, where a number of different organisations cooperate to provide a service or product. Increasingly, organisations do not enter into adversarial one-off contract negotiations, but instead build long-term relationships where improvements (both in terms of quality and efficiency) are achieved through sharing information, expertise and improvement targets.

This replaces competition. It includes cooperation between health, social services and non-statutory bodies, cooperation between provider trusts and cooperation between purchasers and providers. It is similar to the American system of managed care whereby cooperation has replaced competition. It is seen best with the Health Improvement Programme (see Box 2). All organisations in a local area cooperate to develop a plan of action to deal with each major clinical area (e.g. mental health, heart disease). Developments are then made only from this list.

\section{White Papers in Wales and Scotland}

The White Papers in Wales and Scotland are based on similar values but have slight differences to the
English version (NHS Confederation, 1998). All include a Health Improvement Programme developed between different levels of the NHS. In all three countries, trusts will remain separate, free-standing organisations, but there will be a duty on them to work in partnership with an emphasis on health outcomes and improved access to care, not just financial performance. The English version prefers the model of stand-alone mental health trusts, whereas the Scottish version prefers primary care trusts to include mental health, and it is not clear where mental health will sit within the Welsh service.

\section{The effect on commissioning}

The purchaser/provider split has remained, although purchasing is being moved wholesale into primary care with hospital trusts and primary care remaining providers. Health authorities only stay involved in some very specialist tertiary service purchasing. The aim is to stop patients falling through the gaps between organisations. Primary care groups will be purchasing services in their area based on the Health Improvement Programme. This will be based on consensus, negotiation and partnership. As a result, the term 'contracting' is no longer used and has been replaced by the term 'service and financial framework'. This name indicates a link between the service provided, the payment for this service and a less adversarial negotiation resulting in a happy arrangement between the purchaser and provider. Of particular note is that there will be one budget for all purchasing held within the primary care group. This replaces the previous split between budgets for primary care and budgets for secondary care held by health authorities (see Box 3).

\section{Trust configurations and contract currencies}

It is too early to see exactly how some of the changes will develop. Certainly, the commissioning process

Box 2. Health Improvement Programmes

This is an action programme (led by the health authority) to improve health and health care locally. It involves NHS trusts, primary care groups, other primary care professionals, working in partnership with the local authority and engaging other local interests 
should be simpler in that it is clear that it is based on the Health Improvement Programme, which specifies who is involved with what area. There still remain key questions unanswered for mental health.

Will there be more changes in trust configurations?

In England, there has been a move to larger and more specialised trusts. Some mental health trusts include learning disabilities and child and adolescent psychiatry and old age psychiatry, whereas others do not. It is not clear whether there will be imposed trust configurations or not. This has now been clarified somewhat by the National Service Framework (see below).

How measurement will be made within the new NHS?

Problems with activity as a currency have been highlighted and other currencies have been suggested (see Box 4).

Epidemiological. The amount of money allocated to any provider unit could be based purely on a catchment area and its demographic status. The York Psychiatric Index (Peacock \& Smith, 1995) and Mental Illness Needs Index (MINI; Glover et al, 1995) are two such systems. This is more a way of allocating resources than purely looking at contracting currency, but it is simple and can be linked-in with quality measures.

Health-related groups. Much work has been done on this issue. Initially, health-related groups were developed in the USA for the insurance companies. In the UK, health care resource groups (HRGs) have been developed. This has proved very difficult for mental health, and, indeed, although groups of mental illness that clearly appear similar can be gathered together, if one then puts HRGs plus legal status plus Health of the Nation Outcome Scales
Box 4. Methods of monitoring mental health services

Epidemiological

Health-related groups

Outcomes, e.g. HoNOS

Milestones in a programme

Integrated care pathways

Quality measures

(HoNOS) together, then this still only predicts $20 \%$ of the variance of length of stay on a psychiatric ward (i.e. $80 \%$ of the variation is still unexplained). This makes it difficult to use HRGs as a basis for contracting work, but the NHS Executive is still continuing to look at such groupings.

Outcome. It has been suggested that measurement by outcome would be the ideal. HoNOS could be used for this if it were used routinely within services - although there is a danger in using what has been developed as a clinical tool to manage services.

Milestones in a programme. If one looks at the treatment of specific patients, then there might be a number of milestones that could be met and these could be quantified within the service agreement for example, the number of patients assessed for the Care Programme Approach (CPA), or the number who were on medication on discharge from the CPA. Similarly, one could look at all people on a supervision register and determine whether they had all been seen within a month.

Integrated care pathways. The service agreement could specify buying a certain amount of these pathways through a service. An example would be 100 psychiatric in-patients or 100 courses of electrocon-

Box 3. Changes in commissioning in the new NHS

Old NHS

Multiple purchasers e.g. GP fundholders, health authorities, etc.

Annual contracts

Directive and confrontational

Competition

Quality assured through competition

Trusts only have statutory financial duties
New NHS

One purchaser, i.e. the primary care group

Service and financial framework

Negotiation and consensus

Cooperation

Quality assured through regulation and inspectorates

Trusts have financial and clinical quality statutory duties 
vulsive therapy, or even 100 patients on enhanced CPA.

Quality measures. These were increasingly used in the past in contracts and as a lever to implement health authority strategies. Examples are: adherence to CPA, provision of patient information, and even psychiatric sessions available. A new mental health minimum data set is being developed (see Box 5).

\section{National Institute for Clinical Excellence}

The White Paper was keen on evidence-based medicine and uniformity throughout the country. To help with this, NICE will develop guidance on clinicaland cost-effectiveness. These will be in the form of clinical guidelines described as a summation of the state of knowledge on a particular condition at a particular time. As well as these clinical guidelines for specific conditions, there will be guidelines on individual treatments. Therefore, it is likely that guidance will be developed on some of the more controversial areas in psychiatry, such as the use of atypical antipsychotics as first-line treatments or the use of anti-dementia drugs. The intention is to stop 'postcode prescribing', whereby different treatments are available in different areas.

These guidelines will need implementing at a local level. Service agreements with the trusts are bound to include them. The psychiatrist will need to be aware of them and ensure that the trust is implementing them appropriately.

\section{Commission for Health Improvement}

Whereas NICE is involved in developing the clinical guidelines, the Commission for Health Improvement is about implementing these guidelines and other quality measures. The commission was formerly known as CHIMP but after objections from the spindoctors is now shortened to $\mathrm{CHI}$. The $\mathrm{CHI}$ will visit trusts in a rolling programme to ensure that clinical governance is robust and that NICE guidelines are being implemented. It will be like an enforcer of quality standards. It will also check that the NSFs are being implemented and will insist that trusts take part in some national audit studies. It will also have a role in 'troubleshooting' problems within trusts.

\section{Modernising mental health services}

"Care in the community has failed" according to the Secretary of State for Health (NHS Executive, 1998). Many mental health professionals who see their role as providing community care were upset and demoralised by this sound-bite. This document, which concentrates on the needs of working-age adults, sets out the Government's vision and some specific objectives. It proposes the development of 24-hour crisis teams, more acute mental health beds, more hostels and supported accommodation, more home-treatment teams, and more staff training. Extra money is available and is currently being targeted at these areas through the modernisation fund, if the developments are on the Health Improvement Programme.

Whether the new money will make a real difference in localities and whether the Government's preoccupation with safety will subsequently be quenched can only be seen with time.

\section{National Service Framework}

The National Service Framework for Mental Health (NHS Executive, 1999) also only concerns working-age adults. An NSF for older people is expected this year. The NSF is a 'care blueprint' that defines how services are best provided and to what standards.

The purpose of the NSF is to improve quality and reduce unacceptable variations in services. As part of this, standards are: set by NICE and the NSF; delivered by clinical governance; and monitored by $\mathrm{CHI}$.

The NSF fleshes out the policies described in Modernising Mental Health Services and describes the evidence for them. It is more prescriptive than previous documents so that, for instance, it provides a national system for using the CPA with two tiers. It is less prescriptive on trust configurations but suggests that mental health is never part of acute services, and that in cities there are single mental health trusts, and in rural areas mental health should consider joining primary care trusts.

There are seven standards set in the NSF:

- Standard 1 addresses mental health promotion

- Standards 2 and 3 cover primary care and access to services

- Standards 4 and 5 cover effective services for people with severe mental illness

- Standard 6 relates to carers

- Standard 7 draws together the action required to reduce the suicide rate.

\section{The consultant psychiatrist's role in the new NHS}

It could be argued that the new NHS will make little difference to the work of consultant psychiatrists. However, as many have found, management issues 
impinge on clinical work whether we like it or not. Indeed, involving ourselves in management often results in a major impact on the care of people with mental illnesses. If psychiatrists do not take on this role, then other less qualified and less informed people fill the gap. There are five important ways for the consultant psychiatrist to be involved.

First, consultants can be at the forefront of mental health education. There is relatively little said about mental health services in the White Papers, even though mental health services account for over oneeighth of NHS expenditure and mental health problems underlie up to a third of GP consultations. We must work to keep the needs of people with mental illnesses in full view of the public and policy-makers. Consultants can do this by working on local committees and through their links with local, regional or national media. The stigma of being mentally ill is normally projected onto us by managers, nurses and fellow doctors. We are subsequently at the bottom of the medical hierarchy, but by publicising our skills and their benefits to the NHS, we can counteract negative thoughts about mental illness.

Second, it is likely there will be a new configuration of trusts developed, especially in England. Ensuring that the needs of people with mental illnesses are seen as a priority when these new trusts are developed is likely to help those people over time. A key issue will be to ensure that mental health services have the autonomy to lobby the resource allocators directly and have a managerial infrastructure that enables them to develop viable proposals for changes to services.

Third, Health Improvement Programmes will be the centrepiece of commissioning. Consultant psychiatrists have the knowledge of the needs of people with mental illnesses in secondary health care services and often also their needs in primary health care services. It is essential that consultants ensure that their voices are heard and that the key issues are put into the Health Improvement Programme so that they will be funded.

Fourth, PCGs will be allocated money for their population to spend in accordance with the Health Improvement Programme. Psychiatrists have a similar philosophy of care and close working relationships with GPs: we use physical, psychological and social treatments, we develop long-standing relationships with our patients and we often work in primary care settings or patients' homes. This puts us in an enviably influential position and it is essential that we use this position to be involved in the discussions about the distribution of money to ensure that PCGs are well-informed and to champion the cause of people with mental illnesses.

Box 5. Glossary of management jargon

Joined-up thinking

Contract currency

Service and financial framework

Clinical governance

Managed care

Health care resource group (HRG)

Benchmarking

Efficiency

Mental health minimum data set (MHMD)
'New Labour' jargon about coordination and interaction between different groups and agencies

The measure used within a contract to monitor its progress

This has replaced contracting in the new NHS. It is the agreement between the primary care group, health authority and trust with regard to finances and the service specification

This is a system through which NHS organisations are accountable for continually improving the quality of their services and safeguarding high standards of care by creating an environment in which good clinical care will flourish

The USA's system of cooperation between different doctors and organisations that results in peer pressure to improve quality

This is a measure based on case mix (i.e. a combination of different groups of patients) developed for use in the NHS to facilitate resource management and contracting

Comparison between different similar services to determine the most cost-effective service. The other services are then pressured to cut their costs to this level

More or better output is achieved for the same input (usually money) or the same output is achieved for less input

This is information which each trust will have to provide the NHS Executive. It is currently being piloted and will be in use nationally by March 2003 
Fifth, with the development of evidence-based medicine, the psychiatrist is in a unique position to ensure that treatments for mental illnesses are fully evaluated. This will not only be with regard to drug treatments but also psychological treatments. Treatments such as counselling in general practice will be under scrutiny. If there is no evidence for a treatment, then NICE may withdraw it from the NHS.

\section{Conclusion}

The involvement of consultant psychiatrists in commissioning mental health services is paramount. Managers with little knowledge of mental illness normally make the decisions and base these on quantity and idealism rather than real needs of patients. Although it takes time away from clinical care to be involved in the commissioning process, many have found that the consequent improvement in resources for their patients has been worthwhile. Consultant psychiatrists are in a good position to influence the provision of resources and should be seeking a place within their trusts and within the PCGs to let their voices be heard.

\section{References}

Burns, A. \& Bhugra, D. (1995) History and structure of the National Health Service. In Management for Psychiatrists (2nd edn) (eds D. Bhugra \& A. Burns), pp. 3-17. London: Gaskell.

Butler, T. (1993) Changing Mental Health Services: The Politics $\mathcal{E}$ Policy. London: Chapman \& Hall.

Glover, G., Robin, E., Emami, J., et al (1995) A Needs Index for Mental Health Care. London: Royal College of Psychiatrists' Research Unit.

Glynn, J. \& Murphy, M. (1995) Contracting, quality and marketing in the NHS. In Management for Psychiatrists (2nd edn) (eds. D. Bhugra \& A. Burns), pp. 85-99. London: Gaskell.

Griffiths, R. (1983) NHS Management Inquiry: Report to the Secretary of State for Social Services. London: Department of Health and Social Security.

Klein, R. (1995) The New Politics of the NHS (3rd edn). London: Longman.

NHS Confederation (1998) The White Papers for England, Scotland and Wales. Briefing 9. Birmingham: NHS Confederation.

NHS Executive (1995) Clinical Involvement in Contracting. A Handbook of Good Practice. London: NHS Executive.

- (1997a) Designed to Care: Renewing the NHS in Scotland. White Paper. London: NHS Executive.

- (1997b) Putting Patients First: The Future of the NHS in Wales. White Paper. London: NHS Executive.

— (1997c) The New NHS: Modern, Dependable. White Paper. London: NHS Executive.

— (1998) Modernising Mental Health Services: Safe, Sound and Supportive. London: NHS Executive.

- (1999) National Service Framework for Mental Health: Modern Standards and Service Models. London: NHS Executive.

Peacock, S. \& Smith, P. (1995) York Psychiatric Index. Discussion paper 134. York: Centre for Health Economics, University of York.

Simpson, C. J. (1997) Paper chase. Health Service Journal, 13 February.

- (1998) Contracting in mental health. British Journal of Psychiatry, 172, 4-6.

\section{Multiple choice questions}

1. The NHS and Community Care Act 1990:

a introduced the purchaser/provider split

b was influenced by the USA's health care system

c stopped GPs becoming fundholders

$\mathrm{d}$ introduced contracting to the NHS

e produced equity in mental health services.

2. The new NHS:

a is exactly the same throughout the UK

b is based on equity, quality, efficiency and cooperation

c has developed GP fundholding

d has developed primary care groups

e has abandoned evidence-based medicine.

3. Primary care groups:

a may develop into trusts

b have five options in England

c are mental health trusts in Scotland

d include GPs

e will commission mental health services.

4. Commissioning mental health services:

a involves a service and financial framework

$\mathrm{b}$ is the responsibility of NICE

c should involve psychiatrists

$\mathrm{d}$ is based on the Health Improvement Programme

$\mathrm{e}$ is a well-developed process.

5. The Department of Health:

a believes that community care has failed

$\mathrm{b}$ is concerned about the safety of the public

c wants Health Improvement Programmes developed for mental health

d produced Modernising Mental Health Services for older people

e opposes the National Service Framework for mental health.

\section{MCQ answers}

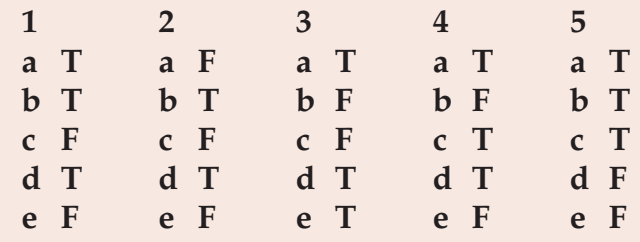

